\title{
Filhos-da-mãe domesticados
}

\section{Ana Vaz Fernandes}

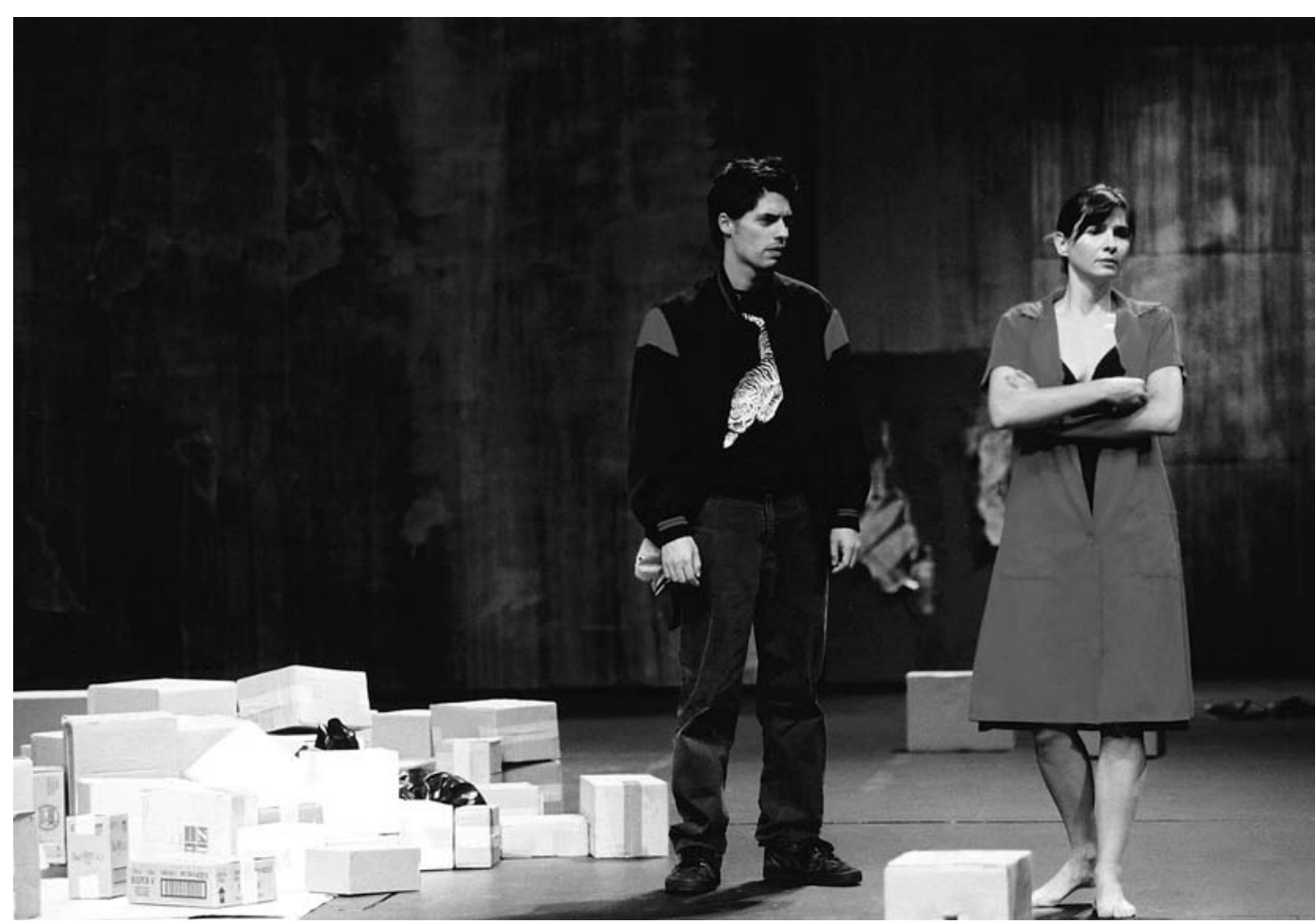

Titulo: Os animais domésticos. Autor: Letizia Russo. Versão portuguesa: Letizia Russo, José Lima e Jorge Silva Melo. Encenação: Jorge Silva Melo, assistido por João Miguel Rodrigues. Cenografia: Rita Lopes Alves e João Calvário. Assistência de cenografia: Sara Nunes. Figurinos: Rita Lopes Alves. Desenho de luzes: Pedro Domingos. Operação de som: Rui Dâmaso e António Venâncio. Interpretação: Américo Silva, Andreia Bento, António Filipe, António Simão, Carla Galvão, Daniel Martinho, Elsa Galvão, Gonçalo Waddington, Joana Bárcia, João Meireles, João Miguel Rodrigues, José Airosa, Pedro Carraça, Sylvie Rocha. Produção: Manuel João Águas. Produção executiva: Sandro Benrós. Co-produção: TNDM II / Artistas Unidos. Local e data de estreia: Teatro Nacional D. Maria II, 22 de Setembro de 2005.

Fomos nós que os inventámos: animal entre os animais domésticos, não há cão que venha ao mundo ensinado a oferecer naturalmente a pata, para satisfação caprichosa do dono. Sabemos que por detrás de cada ordem cumprida se insinua uma força violentadora, ainda quando pelo caminho se constroem dependências afectivas e relações de grande proximidade. 0 recente texto de Letizia Russo dá conta do domínio sobre o Outro, do dispositivo de obrigações e de imposições do processo educativo, bem como dos espartilhos sociais e relacionais dos desejos.

Galardoada com o prémio-revelação UBU de 2003, atribuído a Tomba di cani (Túmulo de cães), Letizia Russo começou no ano de 2000 com o texto Niente e nessuno (Nada e ninguém); desde então, a sua escrita vem tematizando o exercício dos pequenos (grandes) poderes, em universos saturados de indivíduos marginais, onde a sanidade e o equilibrio não se encontram. Os seus textos exploraram as relações humanas, a mesquinhez das hierarquiazinhas e as imposições da vontade miúda de cada um.

Os animais domésticos compõe-se de tudo isto, mas o espectáculo capta também, como uma fotografia lomo, a fúria latente e o nervosismo do "animal doméstico" que foi ensinado, ordenado e composto para viver em formato standard, de acordo com a lógica do domador. Não se trata aqui da figuração de um poder institucional, de relações rei-súbdito, ou sequer de impérios financeiros ou de ditaduras politicas. Os massacres emocionais e físicos acontecem nas micro-comunidades de cada um. Vemos uma mãe e um filho em palco, vemos putas e cegos nas ruas, cães e conversas tristes na paragem do autocarro, jogos fulminantes de sorte e de azar, além do desdém e da morte castigadora.

Estas personagens nasceram de Lisboa: a autora italiana escreveu este texto a convite dos Artistas Unidos, companhia que entre nós se vem distinguindo pelo facto 
Os animais domésticos, de Letizia Russo, enc. Jorge Silva Melo, Artistas Unidos, 2005 (Gonçalo Waddington e José Airosa), fot. Jorge Gonçalves.

de juntar à actividade teatral também a investigação, a crítica

Os animais domésticos

de Letizia Russo enc. Jorge Silva Melo, Artistas Unidos, 2005

(Américo Silva e João Meireles),

fot. Jorge Gonçalves. e a tradução de dramaturgos estrangeiros, frequentemente editados em números especiais da revista Artistas Unidos. 0 número 11 (Julho de 2004) tratou justamente do teatro contemporâneo italiano, o qual mereceu nos anos 90 a atenção da crítica internacional, devido ao boom de dramaturgos emergentes. Nesta edição encontramos, entre outros, autores como Letizia Russo, Davide Enia ou Fausto Paravidino. A publicação dos Livrinhos de Teatro, em parceira com as Edições Cotovia, traduz um empenho generoso em ofertar ao público peças teatrais de novos autores. 0 texto de Os animais domésticos está impresso no número 10 desta colecção.

Patrocinado pela Fundação Calouste Gulbenkian, o trabalho de investigação desenvolvido por Letizia na cidade de Lisboa revelou-se essencial para a constituição do arquivo de referências que atravessa o seu texto. A metrópole nacional é feita de muitas coisas e também de miséria nos cantos mais sujos. Miséria é, aliás, uma espécie de palavra-chave na nova dramaturgia italiana: a miséria social, económica e a miséria dentro de cada sujeito, manifestada em conflitos pessoais e inter-pessoais. Aqui se gera uma vontade perturbada de viver, ainda que "um só dia fora de minha cabeça", como insistentemente repete o Filho (Gonçalo Waddington), o idiota d'Os animais domésticos.

Os idiotas em palco lembram-nos mais Kusturica que Lars von Trier. A decadência e a miséria são entremeadas com humor duro, suscitando o riso nérveo que advém do desequilibrio das personagens, doentes da cabeça e tensamente empestados de si mesmos. Recordo os delírios da Mãe (José Airosa), que evoca um primo exótico e conta ao filho o desejo de voar, feita Tarzan em lianas; os desejos inquietos do seu filho, o qual quer tanto viver um dia fora de si que se sente preso na ignorância, sem saber sequer o nome das coisas. A mulher que este ama (Sylvie Rocha), ensina-Ihe aos poucos as palavras e os caminhos do afecto mas sonha em apanhar um comboio e partir. Pelo meio há cegos que não querem ver, cães com fome e gente com vontade de ganhar dinheiro com o que quer que seja: importa sobreviver.
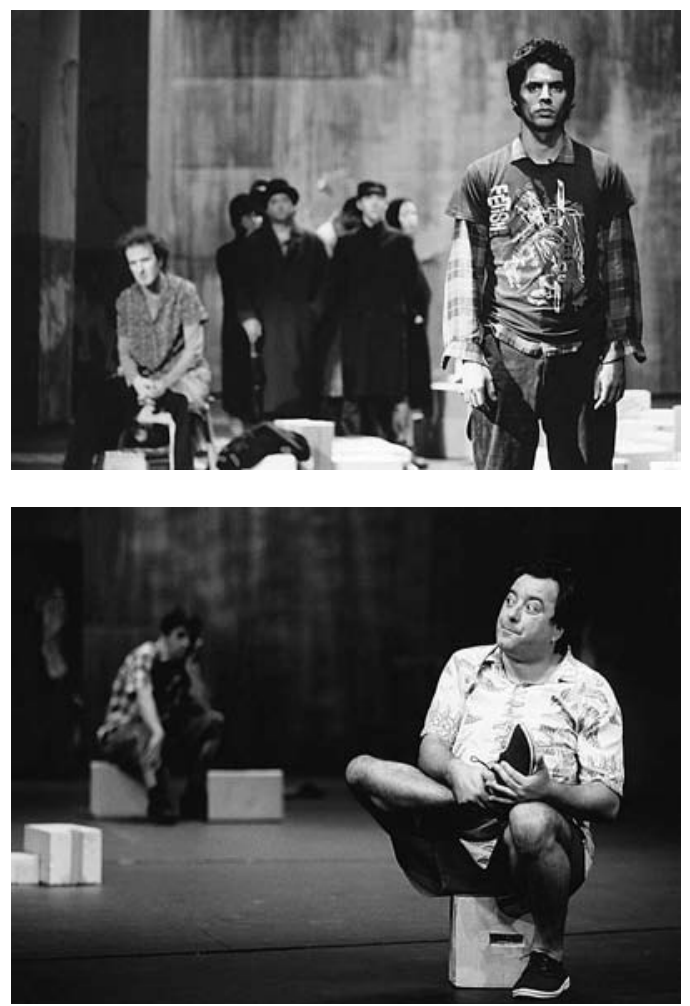

As vontades absurdas destas personagens são conflitos escondidos que emanam insatisfação e frustração, porque os sonhos aqui são cacos partidos, sem concretização provável. Não é difícil encontrar nas ruas lisboetas, como nas ruas de Portugal, os mesmos idiotas a rir e a chorar por dentro. Em qualquer fila de espera poderíamos ouvir ladainhas complicadas, vindas de quem não pode fazer isto ou aquilo. A culpa é assim também expropriada do indivíduo, delegada então no desastre anónimo e de costas largas, sistematicamente recordado e acusado na praça pública.

A peça que Russo escreveu compõe-se de pequenas tragédias quotidianas, ordenadas em palavras cruas e banais. Quase sempre em diálogo, as personagens falam por tudo e por nada, cultivam o desejo inquieto, ao modo daquele querer estar onde não se está, em tempos convocado por António Variações. Prevalece o querer partir, a ambição pelo que está além fronteiras, o frenesim da cidade que passa na rua, lá ao fundo.

A mãe e o filho, personagens centrais, passam o tempo a ver navios. Literal e simultaneamente metafórica, esta expressão caracteriza o ambiente deste espectáculo: num ponto marginal da cidade, engavetada num aleatório beco, onde ao fundo parece passar uma rua mais central, surgenos a educação idiota e letárgica de anos a fio a olhar a estrada. Os "barcos com rodas" (veículos estupidamente 


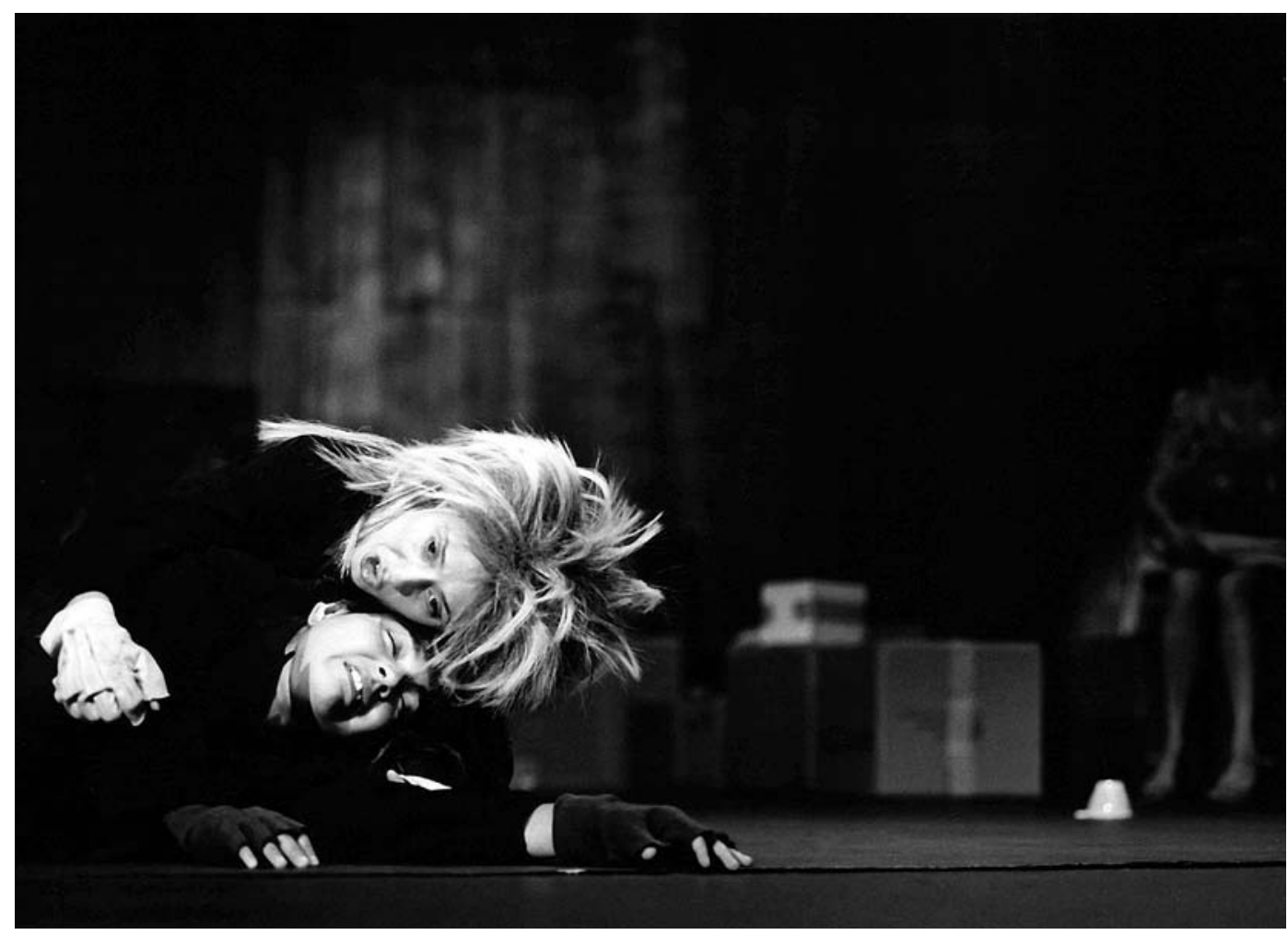

confundidos com navios) são então um simbolo de passagem e de partida. Ali todos sonham saber como é lá fora, como seria deixar tudo para trás (e este tudo é quase nada, pois não parece haver passado nem futuro), como seria esquecer as dividas, as vinganças e os amores, para se procurar um mundo novo, eventualmente admirável. Este é um espectáculo que faz da capital um lugar fragmentado e povoado por histórias decadentes, todos os dias mais negras, até ao fim.

0 encenador tem com a cidade uma relação privilegiada. No meio urbano prolifera a diversidade humana, radicalizam-se as constrições materiais e o gueto explicita as suas fronteiras. Neste sentido, Os animais domésticos potencia um espectáculo pautado pelo ritmo da cidade, entre as horas de ponta, quando alguém se insurge contra o destino e resolve quebrar os tempos mortos. De igual modo, a música intervala e rompe o negrume existencialista dos diálogos, trazendo uma fugaz alegria idiota, logo transmudada em melancolia. Como a urbe, toda a trama é cadenciada pelo tic-tac da rotina de todos os dias: na encenação, o tempo marca-se ainda pela audição pontual do arroto de um homem que passa, algo como o relógio animal do espectáculo.

As conversas, as histórias e os atritos nascem e morrem nas periferias; é em espaços acanhados e medíocres que a jovem escritora italiana encontra um terreno fixo para se mover, criando um círculo espacial fechado, onde a acção rareia, vigorando um texto apurado e de alta intensidade dramática.

Este habitat é feito de caixotes de papelão e colchões desmazelados, onde convivem conhecidos e desconhecidos. A cenografia assinada por Rita Lopes Alves e João Calvário é económica, como é habitual nas apresentações desta companhia. Renega-se a espectacularidade, a multiplicação de elementos cénicos e de adereços. Modera-se a divagação "visualista" e favorece-se uma percepção reflectida, com o texto em primeiro plano.

Jorge Silva Melo deseja um teatro capaz de fazer perguntas, e de fazer perguntas de forma insistente, em torno de um tema. As interrogações das personagens sucedem-se em diálogos, umas vezes filosóficos, outras vezes absurdos, entre o Eu e o Outro ou entre o Eu e o Eu. Os actores vestiram-se com a angústia e a raiva miudinha das personagens. Esta raiva eclode pontualmente em discussões mais furiosas e em pontapés fugazes a qualquer coisa no chão. São momentos que teriam porventura merecido uma energia mais determinada, uma vez que alicerçam a purgação trágica de emoções: são eles que justificam o correctivo imposto às personagens.

No final, a inércia parece domesticar os vivos. Com os olhos postos nos navios que passam, a morte vem punir o filho néscio; já cadáver, no chão, este é ainda condenado pela mãe, num discurso azedo de adeus. 